\title{
Design and Development of a Variable Damping Device for Vibration Control with Electrorheological (ER) Fluid
}

\author{
S. Goilkar ${ }^{1 *}$ \\ ${ }^{1}$ Associate Professor, Finolex Academy of Management and Technology, Ratnagiri, India \\ \{ssgoilkar@gmail.com\}
}

\begin{abstract}
In present scenario, online monitoring and control of dynamic mechanical systems drives an attention of many researchers. Present paper explores design, development and fabrication of an Electrorheological fluid damper done in laboratory, which can be used as a semi-active variable damping device for control of mechanical vibrations. Electrorheological fluid used in this work is nowadays much admired as a smart material and it can be used effectively in conventional viscous damper as a damping fluid of which, rheological properties like viscosity can be changed within milliseconds. When such a damping device is used with a system which can provide high electric voltage, works as a semi-active damper and in absence of high electric voltage it works as a normal passive type viscous damper. This paper also presents some of the findings obtained after the analysis of an Electrorheological fluid damper for which a totally new test rig was designed and fabricated in a laboratory.
\end{abstract}

Keywords: Variable Damping Device, Electrorheological Fluid, Smart materials, Semi-active Damper

\section{Introduction}

Dampers in mechanical vibratory systems are useful devices because; with these dampers the decay or reduction in amplitude of vibration can be achieved. This reduction in amplitude of vibration is mostly associated with dissipation of energy by viscous damping encountered by the bodies moving in fluid [1]. Electrorheological (ER) fluids comes from one of the class of smart materials and are basically a composite material that changes its rheological property especially its yield shear stress after application of high electric potential [2, 3, 4]. The reason behind calling it as a smart material is that, it changes its viscosity in milliseconds after application of an electrical potential [2]. Hence, Electrorheological fluid becomes a suitable challenger to get used in a device like damper from which requirement of variable damping capacity can be fulfilled during running condition of a vibrating systems.

\subsection{Some details of Electrorheological fluids}

Electrorheological fluids are basically colloidal suspensions and this fluid comes in a category of NonNewtonian fluids [5, 6]. In Electrorheological fluids, a low viscosity and substantially dielectric (poor electrical conductor) liquid oil is preferred as base oil and into it a finely divided material like starch, lime stone, gypsum, flour, gelatine, carbon, activated silica gel powders etc. is suspended [7, 8]. In past studies of researchers, these Electrorheological fluids have been considered as a Bingham Plastic material [3, 9]. The behavior of these fluids is expressed as [9],

$\tau=\tau_{\mathrm{y}}+\eta(\partial \gamma / \partial \mathrm{t})$

In above equation of an Electrorheological fluid, it is found out that the yield stress varies with an applied electric field given as,

$\tau_{\mathrm{y}}=\alpha \mathrm{E}^{\beta}$

Where, $\alpha$ and $\beta$ parameters in Eq. 2 depends on the volume fraction of the dispersed particle in the medium and its size respectively $[3,8,9,10]$.

B. Iyer, S. Nalbalwar and R. Pawade (Eds.)

ICCASP/ICMMD-2016. Advances in Intelligent Systems Research.

Vol. 137, Pp. 127-133.

(C) 2017. The authors - Published by Atlantis Press

This is an open access article under the CC BY-NC license (http://creativecommons.org/licens)es/by-nc/4.0/). 


\subsection{Objectives of an Analysis}

1. To prepare an Electrorheological fluid, suitable for the use in a damper, to carry out further analysis.

2. To design, develop and fabricate an Electrorheological fluid damper in a laboratory, to explore its use in vibration control applications.

3. To check a performance of an Electrorheological fluid damper after fabrication of a new test rig which can accommodate the damper assembly and an electromagnetic exciter.

\section{Design and fabrication of an ER fluid damper}

In this research work, design and fabrication of an Electrorheological fluid damper was done with following stages,

1. Theoretical determination of maximum damping force; possible from an Electrorheological fluid which will be used in the damper.

2. Theoretical determination of a damping area and size of an ER damper to achieve the maximum damping force.

3. Determination of electrical parameters of an ER damper.

4. Fabrication of assembly as per the design of an ER damper.

\subsection{Theoretical determination of maximum damping force from an ER fluid}

The behavior of Electrorheological fluid after application of electrical potential can be expressed as per the Eq. 1 and the same can be used to find out the damping capacity of an ER fluid damper. Under forced vibration condition of single degree of freedom system, the equilibrium equation contains inertia force, damping force, spring force and an excitation force. In such equation, contribution from damping is expressed by a damping coefficient which always remains as constant term due to fixed system parameters like damping area, radial gap between piston and cylinder and a viscosity of oil used in conventional viscous damper. However, in mechanical vibrating system containing the Electrorheological fluid damper, it becomes possible to change the value of damping coefficient since the amount of damping in it can be changed by changing its viscosity after application of electric potential during running condition [3]. Therefore, it becomes necessary to take a value of damping coefficient for such an Electrorheological fluid damper as equivalent damping coefficient $\left(\mathrm{C}_{\mathrm{eq}}\right)$ and the equilibrium equation in such case is expressed as,

$M\left(d^{2} x / d t^{2}\right)+C_{e q}(d x / d t)+K \cdot x=F_{0} \sin \omega t$

Where, the term equivalent damping coefficient $\left(\mathrm{C}_{\mathrm{eq}}\right)$, expressed in Eq. 3 can be found out by equating an equation of energy dissipated by an Electrorheological fluid with that of an equation of energy dissipated by a conventional dashpot damper [11,12], and it can be expressed as,

$\mathrm{C}_{\text {eq. }}=2(\mathrm{~A} / \pi)\left[2 \alpha \mathrm{E}^{\beta} / \mathrm{X} \omega+\eta \pi / 2 \mathrm{~d}\right]$

From Eqs. 3 and 4, maximum damping force achievable from an Electrorheological fluid damper can be found out as,

$F_{d(\max )}=A\left(\alpha E^{\beta}+\eta X \omega / d\right)$

\subsection{Theoretical Determination of a damping area and size of an ER damper}

From Eq. 5, the necessary area required to achieve maximum damping force can be found out as,

$\mathrm{A}=\mathrm{F}_{\mathrm{d}(\max )} /\left(\alpha \mathrm{E}^{\beta}+\eta \mathrm{X} \omega / \mathrm{d}\right)$

In Eq. 6, the area A is the total surface area of a damper which is dependent on geometry of an ER damper. In present case, it was decided to design a damper with cylindrical geometry. Therefore, the total damping area of ER damper was decided by choosing 1.5 length to diameter ratio. The length of damper in this case was chosen $50 \%$ more than the diameter to make it suitable for horizontal positioning and it was also thought that the sedimentation of the silica gel particles can be minimized [10]. From Eq. 6, the total area of damper was found 
out as $0.035 \mathrm{~m}^{2}$, andwith this area and $1.5 \mathrm{~L} / \mathrm{D}$ ratio, the length and diameter of inner electrode piston of damper was found out as $13 \times 10^{-2} \mathrm{~m}$ and $8.6 \times 10^{-2} \mathrm{~m}$ respectively.

\section{a. Determination of electrical parameters of an ER damper}

After determining the damper area, electrical parameters were decided. Researchers in past have reported that the D. C. source is more suitable than an A. C. source and an activation threshold voltage of an ER fluid is around $700 \mathrm{~V} / \mathrm{mm}$ electrode gap[2, 9]. Therefore, in this work it was decided to apply voltage with increments of $1 \mathrm{KV} / \mathrm{mm}$ electrode gap. Electrorheological fluids [9], have an initial activation value of normalized current density equal to $9 \mu \mathrm{A} / \mathrm{cm}^{2}$, and with this value it was possible to calculate the current requirement as,

Provide sufficient detail to allow the work to be reproduced. Methods already published should be indicated by a reference: only relevant modifications should be described.

$\mathrm{I}=\mathrm{C} \times \mathrm{A}$

As per the Eq. 7, the range of current to be supplied to the ER damper was decided as 5 to $10 \mathrm{~mA}$, and after these calculations the fabrication process of the ER damper was completed.

\subsection{Determination of electrical parameters of an ER damper}

In order to get prior idea about the probable difficulties, that may arise during fabrication of an ER damper and its test rig, a 3-D solid model of total test set up was created as shown in the Fig. 1.

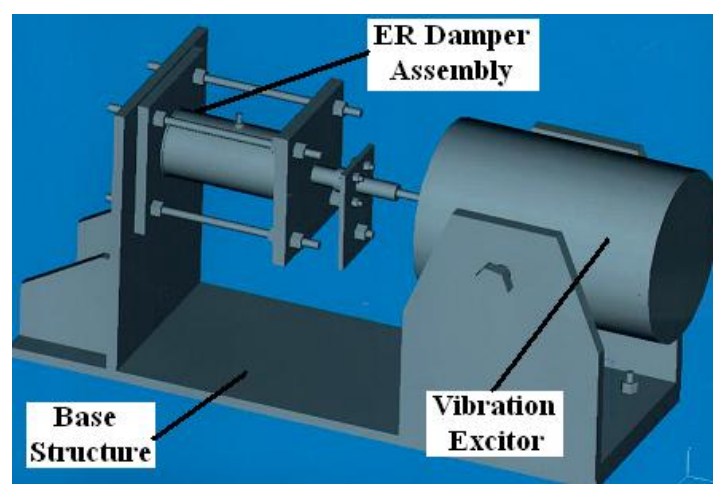

(a)

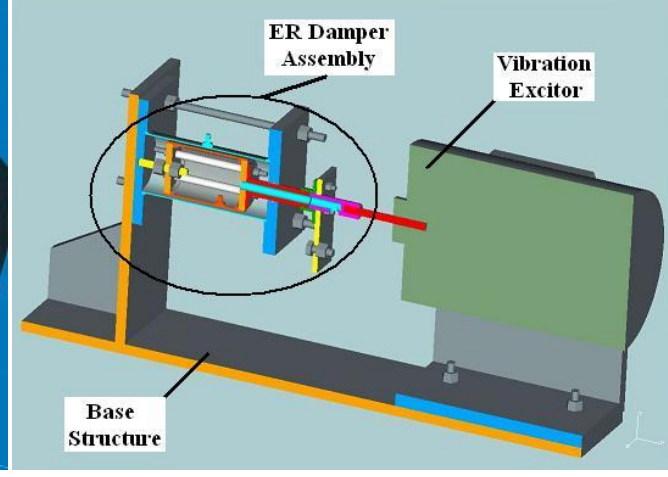

(b)

Fig. 1. Complete 3 - D Solid model of test rig

After designing of damper with theoretical formulation, the total damper assembly was fabricated in the laboratory with three different sub-assemblies as, inner electrode piston assembly, piston rod assembly and outer electrode assembly as shown in the Fig. 2.

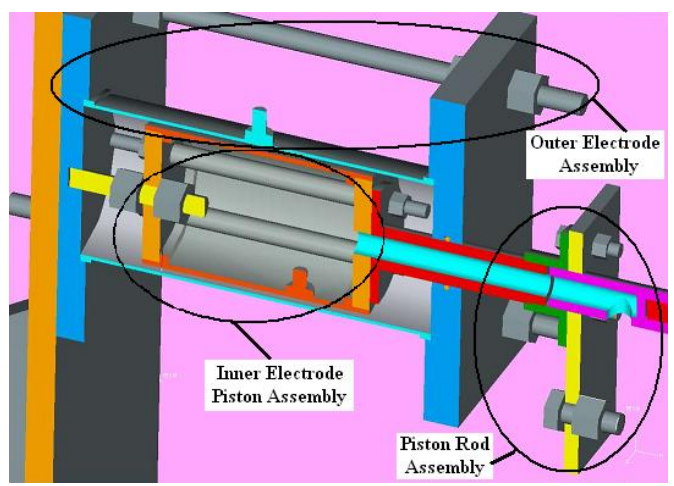

Fig. 2. Complete 3-D Solid model of ER Damper Assembly 


\section{A. Fabrication of inner electrode piston assembly}

The inner electrode piston assembly was made with one inner electrode sleeve of aluminum, four clamping bolts and nuts along with two clamping plates of backelite. The clamping plates of backelite were intentionally chosen to provide insulation against high electric voltage, which was necessary to be supplied during testing of an ER fluid damper. To supply high voltage to inner electrode piston and to connect high voltage cable to it, one aluminum bolt as a cable connector was provided inside the inner electrode piston assembly as shown in Fig. 3.

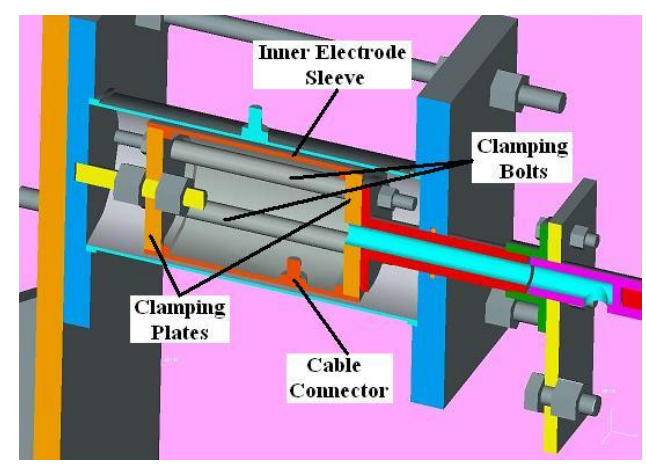

Fig. 3. Inner Electrode Piston Assembly

The outer surface area of inner electrode sleeve, determined by an Eq. 6, was kept as per the designed area.

\section{B. Fabrication of piston rod assembly}

In the fabricated test rig, role of piston rod assembly was vital since it was the main assembly contributing towards the connection of the ER fluid damper and vibration exciter, to transmit the excitations from the exciter. In addition to that, it was also facilitating the supply of high electric voltage to the inner electrode sleeve from the high voltage transformer since it was made as hollow piston rod as shown in Fig. 4. Another important and interesting component used in this assembly was a stinger [13].Initially, during fabrication and testing, a simple mild steel stud was used in between the ER fluid damper and the exciter.

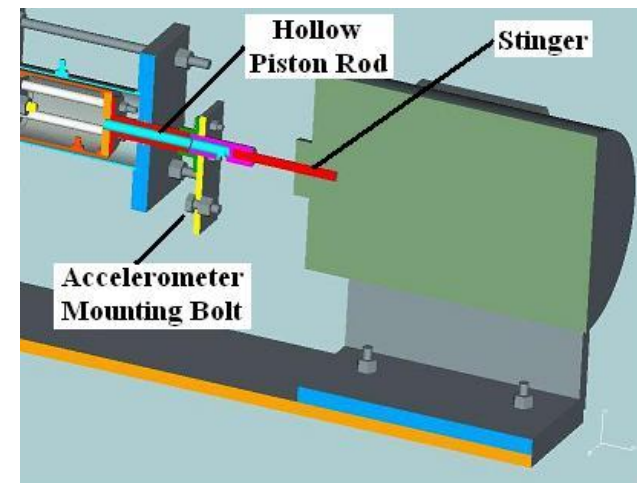

Fig. 4. Piston Rod Assembly of ER Fluid Damper

However, such arrangement with stud was not allowing slight misalignment, but after that the same stud, with same dimensions was made in the laboratory with nylon 66 material which solved the problem completely. This stud made with nylon 66 was nothing but a stinger used in a test rig. In piston rod assembly, an arrangement for mounting an accelerometer was done with an accelerometer mounting nut and bolt as shown in Fig. 4. In this test setup, an accelerometer (B \& K type 4366, Denmark) with magnetic mounting base was used along with a FFT analyzer for data acquisition of vibration signatures during testing.

\section{Fabrication of outer electrode assembly}

The outer electrode assembly of an ER fluid damper was designed in such a way that it can be used as a cylinder which can accommodate the total inner electrode piston assembly. In addition to that, the length of the outer electrode was kept more than the maximum amplitude of vibration, so that the inner electrode can move axially during vibration testing. The outer electrode assembly was made in similar way as that of an inner electrode 
piston assembly with one outer electrode sleeve of aluminum, four clamping bolts and nuts along with two thick clamping plates of backelite as shown in the Fig. 5.

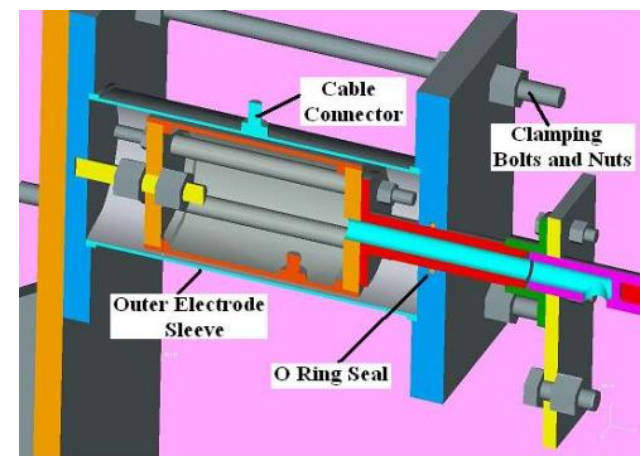

Fig. 5. Outer Electrode Assembly of ER Fluid Damper

The thickness of clamping plates of outer electrode was intentionally chosen more, so that one ' $\mathrm{O}$ ' ring seal can be fitted into it. This arrangement was done to restrict the leakage of an ER fluid from the damper assembly as shown in the Fig. 5. One aluminum bolt as a high voltage cable connector was fixed to the outer electrode sleeve as shown in the Fig. 5.

\section{Experimental Results and Discussion}

Figure 6 illustrates total test setup prepared in the laboratory along with high voltage D. C. power transformer, Vibration exciter, ER Fluid damper assembly and a FFT analyzer which was used during testing.

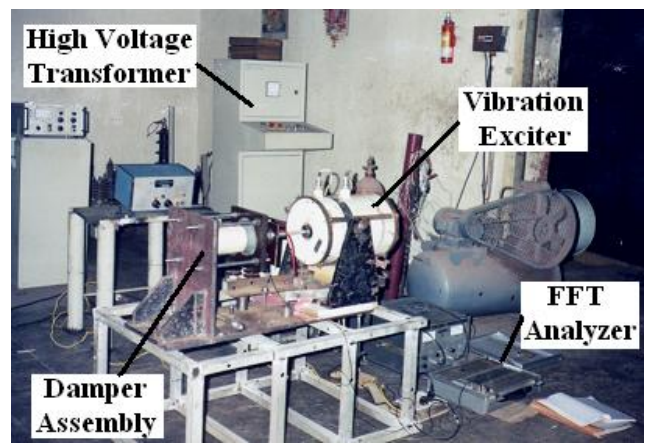

Fig. 6. Electrorheological fluid damper test setup

After preparation of a test setup, the ER fluid damper was tested with varying electric supply voltage with an increment of $1 \mathrm{KV} / \mathrm{mm}$ gap in between the electrodes and with varying frequencies of vibration exciter. Thereafter, the frequency response curves were plotted initially, to find out the values of damping factor $(\xi)$ and then the experimentally determined values of equivalent damping coefficient (Ceq) were obtained [14]. Figure 7 illustrates, increase in equivalent damping coefficient (Ceq) with an increase in electrical voltage, which was applied across the inner and outer electrodes (piston and cylinder) of Electrorheological fluid damper. 


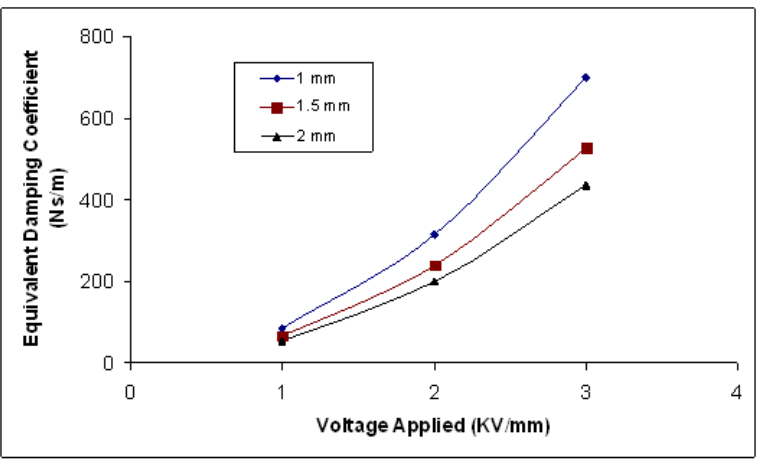

Fig. 7. Effect on equivalent damping coefficient with varying electric voltages and vibration amplitudes

From this Figure 7 it is clear that the amount of damping which can be achieved from an ER damper and the corresponding electric voltage required to be provided can be known and accordingly the strategy can be decided to control the vibration levels of any vibrating system.

\section{Conclusions}

In this work, primary objective to design and develop a variable damping device for vibration control is achieved. The designed damper can provide maximum expected damping force which was calculated initially by the theoretical formulation. However, precise manufacturing of components of an ER fluid damper can still give improved performance since the fabrication in the laboratory done in present case has some limitations.

After performing experiments with the existing designed and fabricated ER damper, it is also observed that, new design can be made which can provide increased area of ER damper, available for damping. Such design may lead to increase in a damping force with reduced overall size of a damper. However, results obtained from this analysis will be extremely useful while making such new designs for further studies and research work.

\section{Nomenclature}

$\tau=$ shear stress

$(\partial \gamma / \partial \mathrm{t})=$ strain rate

$\mathrm{C}_{\mathrm{eq}}=$ Equi. Damping Coeff.

$\omega=$ frequency

$\mathrm{U}=$ damping energy

$\xi=$ damping factor

\author{
$\tau_{\mathrm{y}}=$ yield stress \\ $\mathrm{E}=$ electric field \\ $\mathrm{K}=$ spring stiffness \\ $F_{d}=$ damping force \\ $\mathrm{A}=$ area of electrode piston \\ $\mathrm{I}=$ Current
}

$$
\begin{aligned}
& \eta=\text { viscosity } \\
& M=\text { mass } \\
& \mathrm{X}=\text { displacement } \\
& \mathrm{F}_{0}=\text { applied force } \\
& \mathrm{d}=\text { electrode gap } \\
& \mathrm{C}=\text { Current Density }
\end{aligned}
$$

\section{References}

[1]. Walshaw A. C., Mechanical Vibrations with Applications, First Edition, Ellis Horwood Limited, England, 1984.

[2]. Gandhi M.V., Thompson B.S., and Choi S.B., A new generation of innovative ultra-advanced intelligent composite materials featuring electro-rheological fluids: An experimental investigation, Journal of Composite Materials, 1989, Vol.23, 1232-1255.

[3]. Jordan T. C. and Shaw M. T., Electrorheology, IEEE Transactions on Electrical Insulation, 1989, Vol. 24, No. 5, 849-879.

[4]. Halsey T. C., Electrorheological Fluids, Science, Vol. 258, 1992, 761-766.

[5]. Z. P. Shulman, E. V. Korobko and Yu. G. Yanovskii, The mechanism of the Viscoelastic Behaviour of Electrorheological Suspensions, Journal of Non-Newtonian Fluid Mechanics, Vol. 33, 1989, 181-196. 
[6]. A. A. Mokeev, E. V. Korobko and L. G. Vedernikova, Structural Viscosity of Electrorheological Fluids, Journal of Non-Newtonian Fluid Mechanics, Vol. 42, 1992, 213-230.

[7]. W. M. Winslow, U. S. Patent, 2,417,850, 1947.

[8]. W. M. Winslow, Induced fibration of suspensions, Journal of Applied Physics, 1949, Vol. 20, 11371140 .

[9]. R. C. Ehrgott and S. F. Masri, Experimental Characterization of an Electrorheological Material Subjected to Oscillatory Shear Strains, Journal of Vibration and Acoustics, 1994, Vol. 116, 53-60.

[10]. T. C. Halsey and J. E. Martin, Electrorheological Fluids, Scientific American, 1993, 58-64.

[11]. Hunt J. B., Dynamic Vibration Absorbers, First Edition, Mechanical Engineering Publications Limited, London, 1979.

[12]. Thompson W.T., Theory of Vibration with Application, Third Edition, CBS Publishers, Delhi, 1988.

[13]. D. J. Inman, Engineering Vibrations, Second Edition, Prentice Hall Inc, New Jersey, 2000.

[14]. S. S. Goilkar and J. A. Tamboli, Dynamic Response Analysis of Electrorheological Fluid Damper, Proceedings of the International Conference on Advances in Materials, Product Design and Manufacturing Systems, 2005, 234-239. 